\title{
On Møller energy-momentum complex of a static axially symmetric vacuum space-time
}

\author{
Ragab M. Gad
}

Published online: 16 April 2008

(C) Springer Science+Business Media B.V. 2008

Erratum to: Astrophys Space Sci 302, 141 (2006)

DOI 10.1007/s10509-005-9014-7

In the original article equation (3.5) should read

$\mathfrak{\Im}_{0}^{0}=\frac{1}{4 \pi}\left(r \lambda_{r r}+r \lambda_{z z}+\lambda_{r}\right)$.

Using the relation after equation (1.1), we found

$\mathfrak{s}_{0}^{0}=0$.

The second component in equation (3.7) should read

$\chi_{0}^{03}=\frac{2 m r z}{R^{3}}$.

Consequently, the energy density for the Curzon solution becomes zero.

The abbreviated letters (ELLPBM), in the last paragraph of discussion, becomes (ELLPB).

The online version of the original article can be found under doi:10.1007/s10509-005-9014-7.

R.M. Gad ( $\square)$

Mathematics Department, Faculty of Science, Minia University,

Minia, Egypt

e-mail: ragab2gad@hotmail.com 